Article

\title{
$\delta$-Ctenitoxin-Pn1a, a Peptide from Phoneutria nigriventer Spider Venom, Shows Antinociceptive Effect Involving Opioid and Cannabinoid Systems, in Rats
}

\author{
Bruna Luiza Emerich ${ }^{1}$, Renata C. M. Ferreira ${ }^{2}$, Marta N. Cordeiro ${ }^{3}$, Márcia Helena Borges ${ }^{3}$, \\ Adriano M. C. Pimenta ${ }^{1}$, Suely G. Figueiredo ${ }^{4}$, Igor Dimitri G. Duarte ${ }^{2}$ and \\ Maria Elena de Lima ${ }^{1, *}$ \\ 1 Departmento de Bioquímica e Imunologia, Universidade Federal de Minas Gerais, Av. Antônio Carlos, 6627, \\ Belo Horizonte, MG 31270-901, Brazil; brunaemerich@gmail.com (B.L.E.); apimenta@icb.ufmg.br (A.M.C.P.) \\ 2 Departmento de Farmacologia, Universidade Federal de Minas Gerais, Av. Antônio Carlos, 6627, \\ Belo Horizonte, MG 31270-901, Brazil; recmferreira@gmail.com (R.C.M.F.); dimitri@icb.ufmg.br (I.D.G.D.) \\ 3 Fundação Ezequiel Dias, Rua Conde Pereira Carneiro, 80, Belo Horizonte, MG 30510010, Brazil; \\ martadonascimento.phoneutria@gmail.com (M.N.C.); mhborgesb@gmail.com (M.H.B.) \\ 4 Departamento de Ciências Fisiológicas, Universidade Federal do Espírito Santo, Av. Marechal Campos, \\ 1468, Vitória, ES 29040-900, Brazil; suelygf@gmail.com \\ * Correspondence: melenalima@icb.ufmg.br or lima.mariaelena@gmail.com; Tel.: +55-31-3409-2659
}

Academic Editor: Greta Binford

Received: 29 January 2016; Accepted: 5 April 2016; Published: 12 April 2016

\begin{abstract}
PnTx4(6-1), henceforth renamed $\delta$-Ctenitoxin-Pn1a ( $\delta$-CNTX-Pn1a), a peptide from Phoneutria nigriventer spider venom, initially described as an insect toxin, binds to site 3 of sodium channels in nerve cord synaptosomes and slows down sodium current inactivation in isolated axons in cockroaches (Periplaneta americana). $\delta$-CNTX-Pn1a does not cause any apparent toxicity to mice, when intracerebroventricularly injected $(30 \mu \mathrm{g})$. In this study, we evaluated the antinociceptive effect of $\delta$-CNTX-Pn1a in three animal pain models and investigated its mechanism of action in acute pain. In the inflammatory pain model, induced by carrageenan, $\delta$-CNTX-Pn1a restored the nociceptive threshold of rats, when intraplantarly injected, $2 \mathrm{~h}$ and $30 \mathrm{~min}$ after carrageenan administration. Concerning the neuropathic pain model, $\delta$-CNTX-Pn1a, when intrathecally administered, reversed the hyperalgesia evoked by sciatic nerve constriction. In the acute pain model, induced by prostaglandin $\mathrm{E}_{2}$, intrathecal administration of $\delta$-CNTX-Pn1a caused a dose-dependent antinociceptive effect. Using antagonists of the receptors, we showed that the antinociceptive effect of $\delta$-CNTX-Pn1a involves both the cannabinoid system, through $\mathrm{CB}_{1}$ receptors, and the opioid system, through $\mu$ and $\delta$ receptors. Our data show, for the first time, that $\delta$-Ctenitoxin-Pn1a is able to induce antinociception in inflammatory, neuropathic and acute pain models.
\end{abstract}

Keywords: spider toxin; $\delta$-Ctenitoxin-Pn1a; PnTx4(6-1); Phoneutria nigriventer; spider venom; antinociception

\section{Introduction}

The word pain derives from the Latin poena, which means "penalty" [1], and treating pain has always been a challenge to mankind since ancient times. Nowadays, the International Association for the Study of Pain describes it as "an unpleasant sensory and emotional experience associated with real or potential tissue damage". Further understanding on the mechanisms by which pain signals are interpreted, transmitted and maintained will improve pain treatment strategies. 
A number of novel approaches using animal toxins to relieve pain have been investigated [2-7]. Indeed, peptides derived from animal venoms, including scorpions, spiders, amphibians, snakes and marine organisms, have been explored as antinociceptive agents. Many of them selectively inhibit voltage-activated $\mathrm{Ca}^{2+}$ and $\mathrm{Na}^{+}$channels, acid-sensitive ion channels or glutamate ionotropic receptors [8-12] (for a review please refer to [3,5-7,13,14]). A successful example is the drug (Prialt ${ }^{\circledR}$ ) derived from $\omega$-conotoxin MVIIA, a peptide from Conus magus snail venom, known to have a pronounced analgesic effect resulting from the inhibition of voltage-activated $\mathrm{Ca}^{2+}$ channels $[15,16]$.

It is also known that analgesia can be achieved by modulation of opioid and cannabinoid pathways $[17,18]$. Some peptides that have their mechanism of action based on this modulation have been characterized. One example is Crotalphine, an antinociceptive peptide based on the natural analgesic factor, isolated from the venom of the South American rattlesnake Crotalus durissus terrificus [19], that has its analgesic effect mediated by the release of peripheral dynorphin $\mathrm{A}$, an endogenous agonist of $\mathrm{K}$-opioid receptors, and this release is dependent on cannabinoid receptor $\mathrm{CB}_{2}$ activation [20]. Some scorpion toxins, such as alpha-anatoxin Amm VIII, a weak modulator of $\mathrm{Na}_{\mathrm{v}} 1.2$ channel, and the depressant insect-selective beta-toxin LqqIT2, caused antinociception when injected in mammals, being the activation of endogenous opioid system suggested to be implicated [21]. Additionally, very recently, our group showed that a synthetic peptide called PnPP-19, derived from another toxin of the spider Phoneutria nigriventer, exhibits antinociception in rats via opioid and cannabinoid systems [22].

In the present work, we focused on $\delta$-CNTX-Pn1a, a peptide isolated from the venom of the "armed" spider Phoneutria nigriventer. This spider is responsible for most of the envenomation cases in Brazil. Its venom is mainly composed of peptides, some proteins/enzymes, salts, amino acids and biogenic amines (for a review, please refer to $[5,7,23,24]$ ). Different peptides from this venom have been shown to target ion channels, as $\mathrm{Na}_{\mathrm{v}}$ channels [25,26]; $\mathrm{Ca}_{\mathrm{v}}$ channels [27-29], and $\mathrm{K}_{\mathrm{v}}$ channels [30]. Another interesting group of peptides isolated from the venom of $P$. nigriventer comprises the insect toxins [31-35], which include PnTx4(6-1) or $\delta$-CNTX-Pn1a, the toxin studied in this work, previously characterized to target insect sodium channels [9]. Herein we renamed this toxin, previously named PnTx4(6-1), taking into account the nomenclature proposed by King and co-authors [36], and we also highlight this new nomenclature for the other P. nigriventer peptides. $\delta$-CNTX-Pn1a is a 48-amino-acid polypeptide, with 5 disulfide bridges (MW 5244.6 Da) [31]. The cDNA encoding this toxin was isolated and the toxin probably has a signal peptide followed by a propeptide [37]. This toxin binds to site 3 of sodium channels in cockroach nerve cord synaptosomes (Periplaneta americana) [9]. Indeed, although $\delta$-CNTX-Pn1a slows down the inactivation of sodium currents in cockroach-isolated axons, it does not affect the currents in rat skeletal muscle $\left(\mathrm{rNa}_{\mathrm{v}} 1.4 / \mathrm{rSKM} 1\right)$ or brain $\left(\mathrm{rNa}_{\mathrm{v}} 1.2 / \mathrm{rBIIA}\right)$ [9]. Moreover, at a high concentration $(30 \mu \mathrm{g})$ it does not cause apparent toxicity to mice, when intracerebroventricularly (i.c.v) injected [31]. However, an action of this toxin in other sub-types of $\mathrm{Na}_{\mathrm{v}} \mathrm{s}$ from mammals cannot be discarded, as we recently demonstrated for the recombinant PnTx4(5-5) (rГ-ctenitoxin-Pn1a), another insect toxin from $P$. nigriventer venom, which shows $63 \%$ of identity with $\delta$-CNTX-Pn1a [35]. $\mathrm{r} \Gamma$-ctenitoxin-Pn1a was able to inhibit sodium currents on all mammalian $\mathrm{Na}_{\mathrm{v}}$ channels tested $\left(\mathrm{Na}_{\mathrm{v}} 1.2\right.$ to $\left.\mathrm{Na}_{\mathrm{v}} 1.6\right)$, with the highest current inhibition on $\mathrm{Na}_{\mathrm{v}} 1.3\left(38.43 \% \pm 8.04 \%, \mathrm{IC}_{50}=1.5 \mu \mathrm{M}\right)$. Despite its apparent lack of toxicity to mammals, we previously showed that $\Gamma$-ctenitoxin-Pn1a native reversibly inhibited the current of $\mathrm{N}$-methyl-D-aspartate (NMDA) subtype of ionotropic glutamate receptors in rat hippocampal neurons [32]. In addition, we demonstrated that this toxin causes antinociception when peripherally injected in rats [38]. Additionally, it was recently shown that $\Gamma$-ctenitoxin-Pn1a promotes neuroprotection under insults of high levels of glutamate, in primary-cultured corticostriatal neurons from wild type mice, as well as from a mouse model of Huntington's disease [39]. It is well known that NMDA receptors are involved in nociception and that NMDA antagonists can produce antinociception [40,41].

Taking into account that $\delta$-CNTX-Pn1a shows significant similarity with PnTx4(5-5) ( $\Gamma$-ctenitoxin-Pn1a), which antagonized NMDA-receptor current in rat neurons and induced 
antinociception when peripherally tested in rats [38], this work aims at looking for the putative antinociceptive effect of $\delta$-CNTX-Pn1a in different experimental pain models in rats: inflammatory, neuropathic and nociceptive. After confirming the antinociceptive effect of $\delta$-CNTX-Pn1a in all these pain models, we proceeded to investigate the mechanisms underlying its analgesic properties, revealing the involvement of endogenous opioid and cannabinoid systems.

\section{Results}

\subsection{Effect of $\delta$-CNTX-Pn1a on Carrageenan-Induced Inflammatory Hyperalgesia}

Administration of $5 \mu \mathrm{g}$ of $\delta$-CNTX-Pn1a, $2 \mathrm{~h}$ and $30 \mathrm{~min}$ after carrageenan $(\mathrm{Cg})$, significantly increased the nociceptive threshold following carrageenan-induced inflammation. However, the administration of $\delta$-CNTX-Pn1a by $30 \mathrm{~min}$ or $1 \mathrm{~h}$ and $30 \mathrm{~min}$ after $\mathrm{Cg}$ did not reverse hyperalgesia (Figure 1).

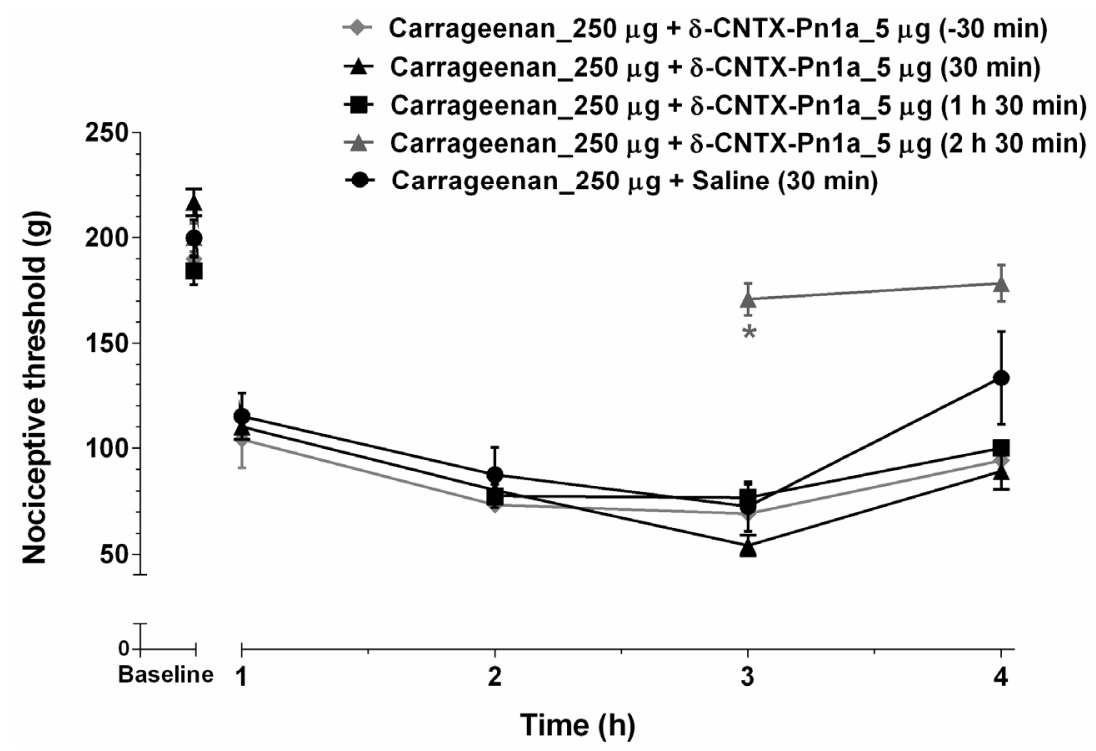

Figure 1. $\delta$-CNTX-Pn1a antinociceptive effect following carrageenan-induced hyperalgesia. Rats were injected with $250 \mu \mathrm{g}$ of carrageenan $(\mathrm{Cg})$ into the right hind paw and then $5 \mu \mathrm{g}$ of $\delta$-CNTX-Pn1a $(1 \mathrm{nmol})$ was intraplantarly administered into the same site, at different times ( $-30 \mathrm{~min}, 30 \mathrm{~min}, 1 \mathrm{~h}$ and $30 \mathrm{~min}$, and $2 \mathrm{~h}$ and $30 \mathrm{~min}$ related to Cg injection). Nociceptive threshold was measured hourly $1 \mathrm{~h}$ after $\mathrm{Cg}$ injection. Each symbol represents MEAN \pm SEM. $n=4$ rats per group. Data were analyzed using ANOVA and Bonferroni post-test. $p<0.05$ compared to $\mathrm{Cg}+$ Saline $\left.{ }^{*}\right)$.

\subsection{Effect of $\delta$-CNTX-Pn1a on Neuropathic Hyperalgesia}

Intrathecal administration of $0.5 \mu \mathrm{g}$ of $\delta$-CNTX-Pn1a reversed the hyperalgesia induced by surgical sciatic nerve constriction. The analgesic effect was observed $5 \mathrm{~min}$ after administration and this effect progressively decreased with time, not being detected after 20 min (Figure 2).

\subsection{Effect of $\delta$-CNTX-Pn1a on Prostaglandin $E_{2}$-Induced Hyperalgesia and Comparison between} $\delta$-CNTX-Pn1a and w-Conotoxina MVIIA Antinociceptive Activity

$\mathrm{PGE}_{2}$ is known to decrease the nociceptive threshold of nociceptors, exerting a critical role in the generation and maintenance of nociception [42]. We investigated the effect of $\delta$-CNTX-Pn1a on $\mathrm{PGE}_{2}$-induced hyperalgesia and showed that this peptide increased, in a dose-dependent manner, the nociceptive threshold of rats. The highest tested dose $(2 \mu \mathrm{g})$ induced a potent antinociception, which persisted for $30 \mathrm{~min}$. This effect was less durable for the other tested doses ( 0.5 and $1 \mu \mathrm{g})$ (Figure 3). 


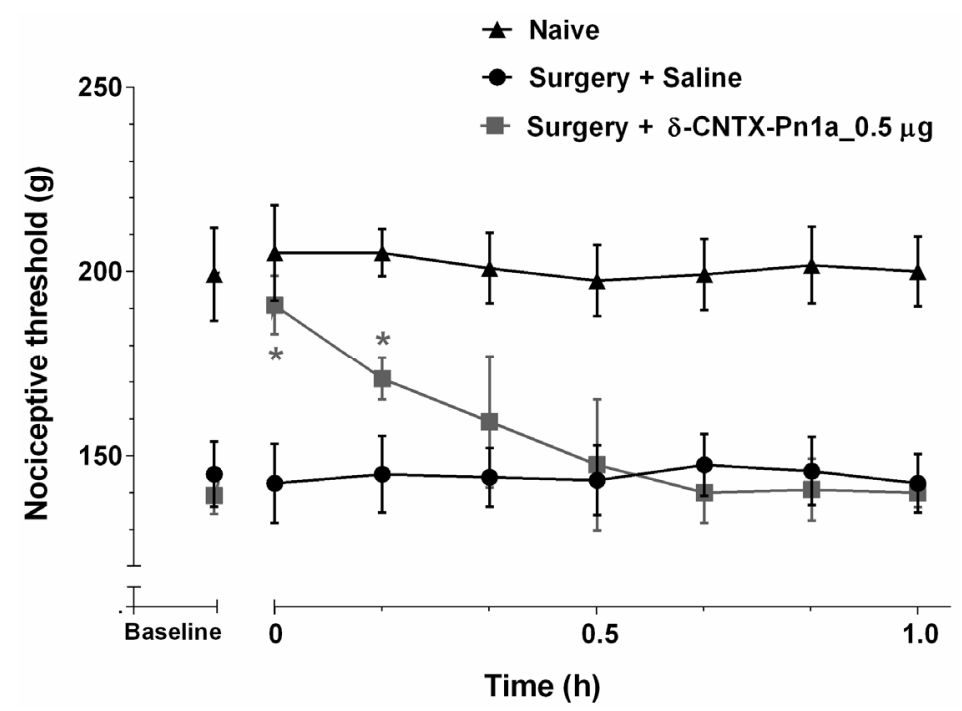

Figure 2. $\delta$-CNTX-Pn1a antinociceptive effect on neuropathic hyperalgesia induced by surgical sciatic nerve constriction (14 days). Rats received $0.5 \mu \mathrm{g}$ of $\delta$-CNTX-Pn1a $(0.1 \mathrm{nmol})$ or saline (control) through intrathecal injection. Rats that were not submitted to surgical intervention and not treated were labeled as naive. Nociceptive threshold was measured every $10 \mathrm{~min}$, starting $5 \mathrm{~min}$ after the injections. Each symbol represents MEAN \pm SEM. $n=4$ rats per group. Data were analyzed using ANOVA and Bonferroni post-test. $p<0.05$ compared to Surgery + Saline $\left.{ }^{*}\right)$.

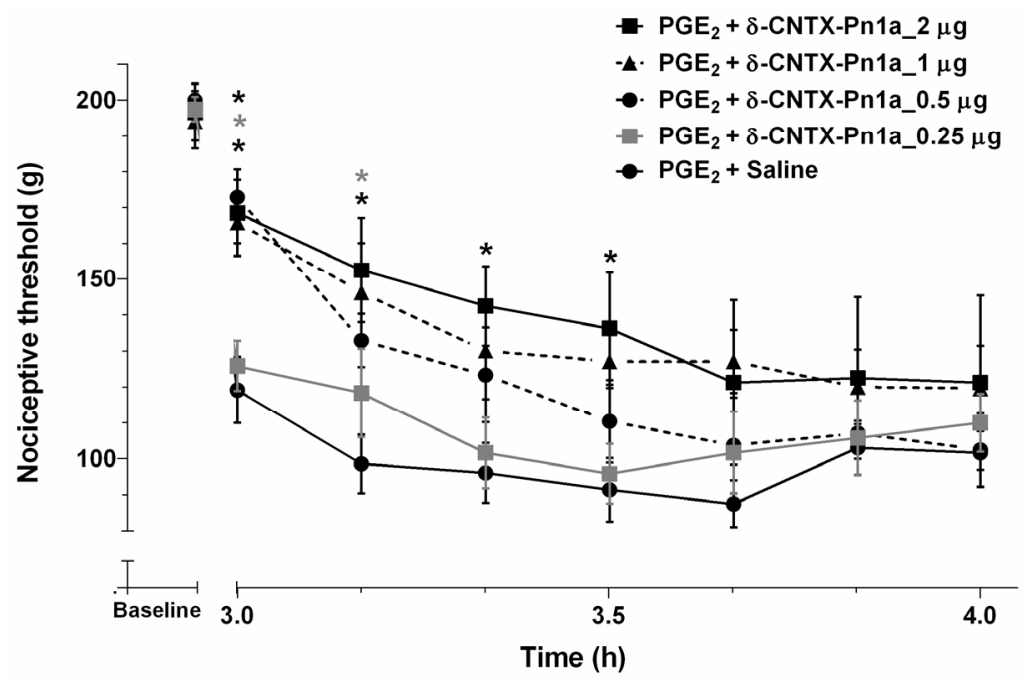

Figure 3. $\delta$-CNTX-Pn1a antinociceptive effect following prostaglandin $E_{2}$-induced hyperalgesia. Prostaglandin $\mathrm{E}_{2}\left(\mathrm{PGE}_{2}\right)(2 \mu \mathrm{g} / \mathrm{paw})$ was administered through intraplantar injection. Rats received $0.25,0.5,1$ and $2 \mu \mathrm{g}$ of $\delta$-CNTX-Pn1a $(0.05,0.1,0.2$ and $0.4 \mathrm{nmol})$ or saline (control) through intrathecal administration, $2 \mathrm{~h}$ and $55 \mathrm{~min}$ after $\mathrm{PGE}_{2}$ injection. Nociceptive threshold was measured every $10 \mathrm{~min}$, starting $5 \mathrm{~min}$ after peptide or saline injections. Each symbol represents MEAN \pm SEM. $n=4$ rats per group. Data were analyzed using ANOVA, and Bonferroni post-test. $p<0.05$ compared to $\mathrm{PGE}_{2}+$ Saline $\left({ }^{*}\right)$.

The antinociceptive effect produced by $0.5 \mu \mathrm{g}$ (minimum effective dose) of $\delta$-CNTX-Pn1a was compared to the antinociceptive effect of $\omega$-conotoxin MVIIA on $\mathrm{PGE}_{2}$-induced hyperalgesia. The peptide $(0.5 \mu \mathrm{g})$ was intrathecally administered and the nociceptive threshold was measured $5 \mathrm{~min}$ after the administration. The antinociceptive effect was similar for both peptides (Figure 4). 


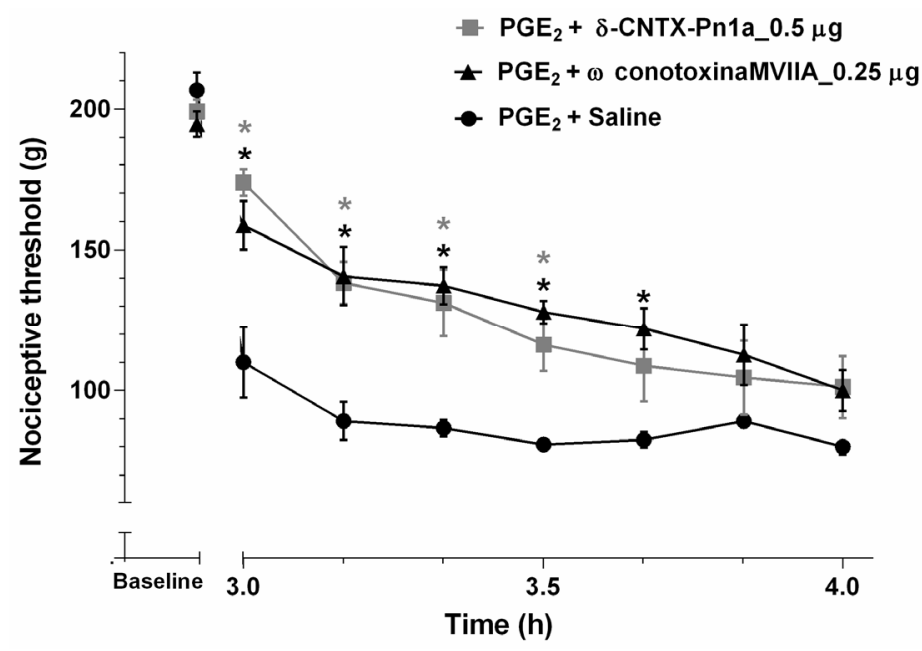

Figure 4. Antinociceptive effect of $\delta$-CNTX-Pn1a and $\omega$-conotoxin MVIIA following prostaglandin $\mathrm{E}_{2}$-induced hyperalgesia. Rats received $0.5 \mu \mathrm{g}$ of $\delta$-CNTX-Pn1a $(0.1 \mathrm{nmol})$ or $0.25 \mu \mathrm{g} \omega$-conotoxin MVIIA $(0.1 \mathrm{nmol})$ or saline (control) through intrathecal administration $2 \mathrm{~h}$ and $55 \mathrm{~min}$ after intraplantar injection of prostaglandin $\mathrm{E}_{2}\left(\mathrm{PGE}_{2}\right)(2 \mu \mathrm{g} / \mathrm{paw})$. Nociceptive threshold was measured every $10 \mathrm{~min}$, starting $5 \mathrm{~min}$ after toxin or saline injections. Each symbol represents MEAN \pm SEM. $n=4$ rats per group. Data were analyzed using ANOVA and Bonferroni post-test. ${ }^{*} p<0.05$ compared to $\mathrm{PGE}_{2}+$ Saline.

\subsection{Involvement of Cannabinoid and Opioid Systems in $8-C N T X-P n 1 a$ Antinociceptive Effect}

The mechanism underlying $\delta$-CNTX-Pn1a effect on the hyperalgesia induced by the inflammatory mediator $\mathrm{PGE}_{2}$ was also investigated. For this, we verified the possible effect of $\delta$-CNTX-Pn1a on the cannabinoid and opioid pathways. In order to investigate the involvement of the cannabinoid system, animals were treated with AM251 $(40,80,160$ and $320 \mu \mathrm{g})$, a selective $\mathrm{CB}_{1}$ receptor antagonist, or AM630 $(100 \mu \mathrm{g})$, a selective $\mathrm{CB}_{2}$ receptor antagonist, both administered $10 \mathrm{~min}$ before the peptide. AM251 reversed, in a dose-dependent manner, the antinociceptive effect of $\delta$-CNTX-Pn1a, intrathecally administered (i.t.), on $\mathrm{PGE}_{2}$-induced hyperalgesia (Figure 5a). On the other hand, $100 \mu \mathrm{g}$ of AM630 showed no significant effect on $\delta$-CNTX-Pn1a antinociceptive effect (Figure 5b).

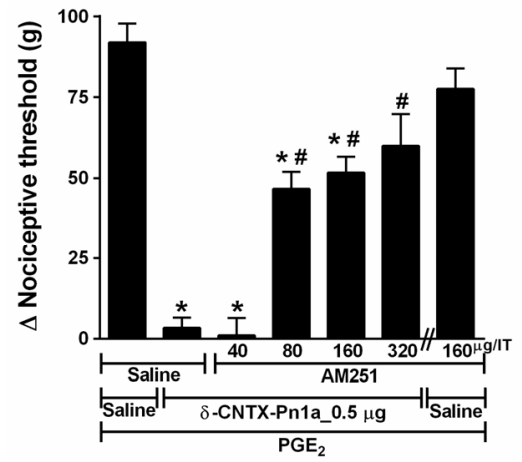

(a)

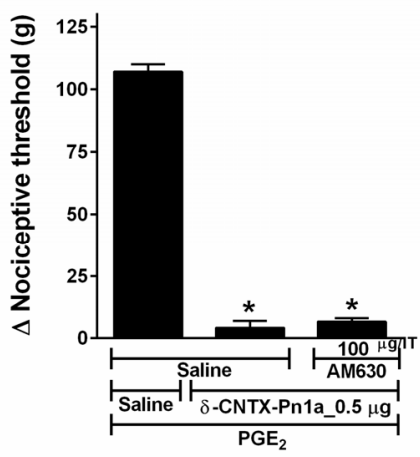

(b)

Figure 5. Effect of cannabinoid antagonists on $\delta$-CNTX-Pn1a antinociception following prostaglandin $\mathrm{E}_{2}$-induced hyperalgesia. Rats received AM251 (a) or AM630 (b) through intrathecal route $2 \mathrm{~h}$ and 45 min after prostaglandin $\mathrm{E}_{2}\left(\mathrm{PGE}_{2}\right)$ injection $(2 \mu \mathrm{g} / \mathrm{paw})$. $\delta$-CNTX-Pn1a, $0.5 \mu \mathrm{g}(0.1 \mathrm{nmol})$, or saline (control) were intrathecally injected $10 \mathrm{~min}$ after the antagonists. Nociceptive threshold was measured 5 min after peptide or saline injection. Vertical bars represent MEAN \pm SEM. $n=4$ rats per group. Data were analyzed using ANOVA and Bonferroni post-test. $p<0.05$ compared to $\mathrm{PGE}_{2}+$ Saline $\left(^{*}\right)$ or $\mathrm{PGE}_{2}+\delta$-CNTX-Pn1a + Saline (\#). 
In order to explore the involvement of the opioid system, animals were treated with opioid receptor antagonists. The non-selective opioid antagonist, naloxone, reversed the antinociceptive effect of $\delta$-CNTX-Pn1a (Figure 6a). Selective antagonists for $\mu$ (Clocinamox) and $\delta$ (Naltrindole) receptors significantly decreased $\delta$-CNTX-Pn1a antinociception (Figure $6 \mathrm{~b}, \mathrm{c}$ ). The selective antagonist for $\mathrm{k}$ receptor (Nor-BNI) showed no significant effect on $\delta$-CNTX-Pn1a antinociception (Figure 6d).

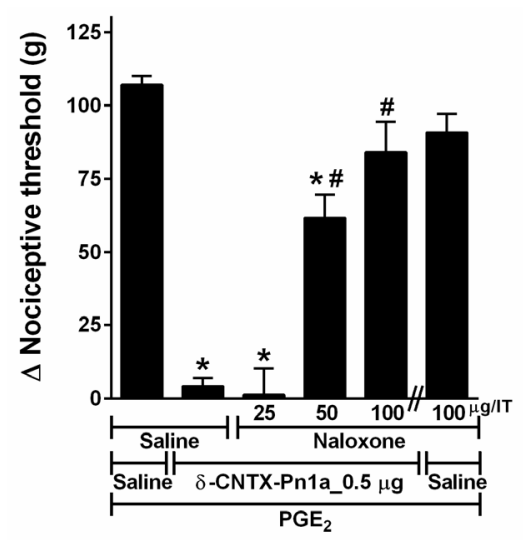

(a)

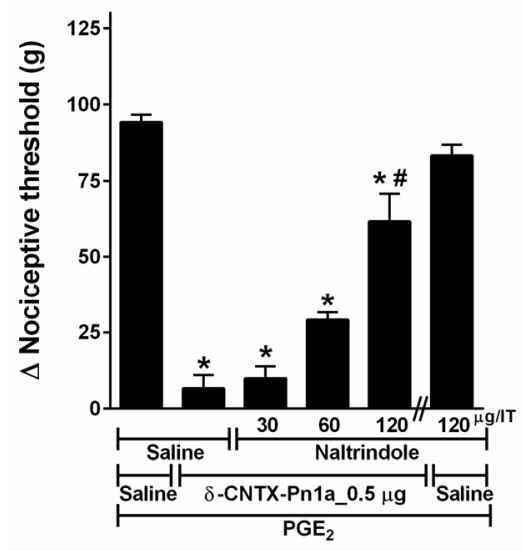

(c)

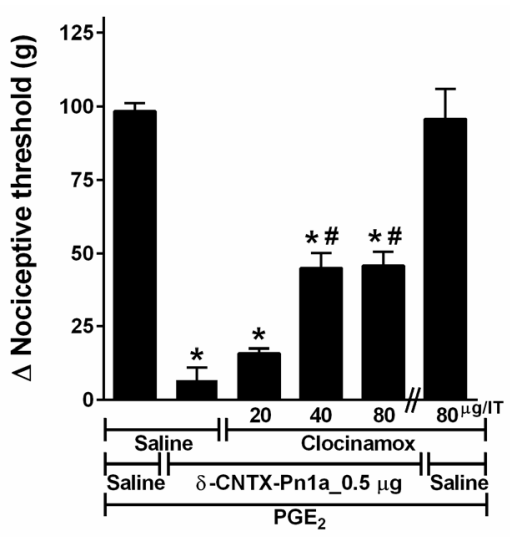

(b)

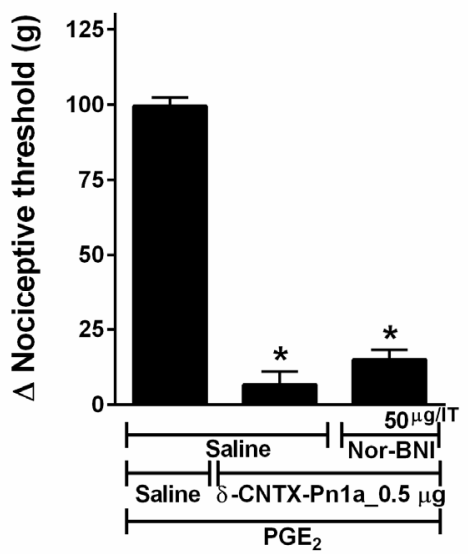

(d)

Figure 6. Effect of opioid antagonists on $\delta$-CNTX-Pn1a antinociception following prostaglandin $\mathrm{E}_{2}$-induced hyperalgesia. Rats received Naloxone (a); Clocinamox (b); Naltrindole (c) or Nor-BNI (d) through intrathecal route $2 \mathrm{~h}$ and $25 \mathrm{~min}$ after prostaglandin $\mathrm{E}_{2}\left(\mathrm{PGE}_{2}\right)$ injection $(2 \mu \mathrm{g} / \mathrm{paw})$. $\delta$-CNTX-Pn1a, $0.5 \mu \mathrm{g}(0.1 \mathrm{nmol})$ or saline (control) were intrathecally injected $30 \mathrm{~min}$ after the antagonists. Nociceptive threshold was measured $5 \mathrm{~min}$ after toxin or saline injection. Vertical bars represent MEAN \pm SEM. $n=4$ rats per group. Data were analyzed using ANOVA and Bonferroni post-test. $p<0.05$ compared to $\mathrm{PGE}_{2}+$ Saline $\left({ }^{*}\right)$ or $\mathrm{PGE}_{2}+\delta$-CNTX-Pn1a + Saline (\#).

\section{Discussion}

The antinociceptive potential of animal toxins has been subject of several investigations that demonstrate the antinociceptive effect of venoms and many of their derivative peptides [5,6,12,43-46]. Our results show the analgesic effect of $\delta$-CNTX-Pn1a in inflammatory, neuropathic and nociceptive in vivo pain models. Moreover, we reveal that the antinociceptive effect of $\delta$-CNTX-Pn1a in the nociceptive pain model involves both opioid and cannabinoid endogenous systems.

Intraplantar administration of $\delta$-CNTX-Pn1a inhibited inflammatory pain only when administered $2 \mathrm{~h}$ and $30 \mathrm{~min}$ after carrageenan injection. This effect may be related to the kinetics of mediators release in carrageenan-induced inflammation. In fact, many mediators are involved in carrageenan inflammation, including histamine, serotonin, kinins and prostaglandins [47]. The mediators involved 
in this nociceptive effect are most likely prostaglandins, which are known to decrease the threshold of nociceptor activation two hours after carrageenan administration [48].

The pharmacological treatment of neuropathic pain remains a challenge. Indeed, the current pharmacological clinical management of neuropathic pain achieves clinically significant pain relief in less than $50 \%$ of patients [49]. Here, we tested $\delta$-CNTX-Pn1a in the neuropathic pain model and found that this peptide reversed the hyperalgesia caused by sciatic constriction. The effect of $\delta$-CNTX-Pn1a was significant up to 10 min after injection, decreasing progressively over time, and losing effect after $20 \mathrm{~min}$.

According to Dalmolin and co-authors [46] and Oliveira and co-authors [50], two peptides isolated from the venom of Phoneutria nigriventer induce marked antinociceptive effect in an experimental model of neuropathic pain. Both peptides are able to modulate voltage-sensitive calcium channels: Tx3-3 ( $\omega$-ctenitoxin-Pn2a) blocks P/Q and R types, while Tx3-5 ( $\mathrm{U}_{7}$-ctenitoxin-Pn1a) is a selective and potent blocker of L type. In low doses (3-300 fmol/site), Tx3-5 ( $\mathrm{U}_{7}$-ctenitoxin-Pn1a) was able to produce antinociception in postoperative, neuropathic and cancer-related pain models. The analgesic potential of these toxins isolated from Phoneutria nigriventer venom seems evident. However, future studies using different concentrations of $\delta$-CNTX-Pn1a may reveal better toxin-induced reversal of the hyperalgesia in our neuropathic model.

It is known that loss of spinal opioid receptors and increased activity of physiological opioid antagonist systems occur in neuropathic pain. In contrast, no biologically relevant decrease in the number of $\mathrm{CB}_{1}$ receptors was evident after dorsal injury [49]. Although we did not investigate the mechanism of action of $\delta$-CNTX-Pn1a in the neuropathic pain model, the effect of the peptide on $\mathrm{CB}_{1}$ receptors, observed for the nociceptive pain model discussed below, may encourage future investigations regarding a possible relationship between these receptors and the peptide analgesia observed in our neuropathic pain model.

When intrathecally administered, $\delta$-CNTX-Pn1a showed a dose-dependent analgesic effect in $\mathrm{PGE}_{2}$-induced hyperalgesia. This effect was comparable to the antinociceptive effect of $\omega$-conotoxin MVIIA, a peptide purified from the venom of the snail Conus magus. However, these two peptides apparently have distinct mechanisms of action. Indeed, the synthetic version of $\omega$-conotoxin MVIIA is a powerful analgesic drug (Prialt ${ }^{\circledR}$, Dublin, Ireland) that has a unique mechanism of action involving potent and selective blockage of $N$-type calcium channels [16]. On the other hand, the mechanism underlying the analgesic effect of $\delta$-CNTX-Pn1a involves both cannabinoid and opioid receptors. It is well known that these receptors are involved in antinociceptive pathways. However, there are few studies regarding the effect of animal toxins on these receptors. Here, we show that only $A M 251$, a selective $\mathrm{CB}_{1}$ receptor antagonist, when intrathecally administered, antagonizes the antinociceptive effect of $\delta$-CNTX-Pn1a in PGE 2 -induced hyperalgesia (Figure 5a). Using naloxone, a nonselective opioid receptor antagonist, the antinociceptive effect of $\delta$-CNTX-Pn1a was reverted (Figure 6a). In addition, we show that $\mu$ and $\delta$ opioid, but not $\mathrm{k}$ receptors, are involved in $\delta$-CNTX-Pn1a antinociception (Figure 6b,c). Pnpp19, a peptide synthetized by our group, in addition to potentiating erectile function in rats, showed antinocieptive activity against $\mathrm{PGE}_{2}$ hyperalgesia through activation of $\mu$ and $\delta$ opioid, and $\mathrm{CB}_{1}$ cannabinoid receptors. This peptide also seems to be able to indirectly induce antinociception through inhibition of a neuronal endopeptidase responsible for the cleavage of the endogenous opioid peptide encephalin [22]. Different from these findings, Crotalphine peptide reduced $\mathrm{PGE}_{2}$-induced hyperalgesia through an increased activation of both $\mathrm{k}$-opioid and $\mathrm{CB}_{2}$ cannabinoid receptors, being this effect mediated by dynorphin $\mathrm{A}$ [20]. This result reinforces the interaction between cannabinoid and opioid systems, as observed in our work and highlights the complexity of the nociceoptitive pathways.

Finally, we recently showed that $\mathrm{rPnTx} 4(5-5)$ ( $\mathrm{r} \Gamma$-ctenitoxin-Pn1a), another insect toxin from $P$. nigriventer showing $63 \%$ of similarity to $\delta$-CNTX-Pn1a, obtained by heterologous expression in E. coli, besides strongly slowing down the inactivation of $\mathrm{Bg} \mathrm{Na}_{\mathrm{v}}$ (a sodium channel from Blatella germanica cockroach) also inhibited sodium currents on all tested $\mathrm{Na}_{\mathrm{v}} \mathrm{s}$ from mammals $\left(\mathrm{Na}_{\mathrm{v}} 1.2\right.$ to 
$\mathrm{Na}_{\mathrm{v}}$ 1.6). It is worth noting that $\mathrm{r} \Gamma$-ctenitoxin-Pn1a, as observed for $\delta$-CNTX-Pn1a, did not show any apparent toxicity to mice, when i.c.v. injected (up to $30 \mu \mathrm{g}$ ). $\mathrm{r} \Gamma$-ctenitoxin-Pn1a caused the highest current inhibition on $\mathrm{Na}_{\mathrm{v}} 1.3\left(38.43 \% \pm 8.04 \%, \mathrm{IC}_{50}=1.5 \mu \mathrm{M}\right)$ [35]. In addition to $\mathrm{Na}_{\mathrm{v}} 1.3$, some subtypes of $\mathrm{Na}_{\mathrm{V}} \mathrm{s}$, especially $\mathrm{Na}_{\mathrm{V}} \mathrm{s} 1.7,1.8$ and 1.9, have been described to play a significant role in pain processes. However, in order to investigate if the antinociceptive effect of these insect-toxins involves the inhibition of sodium channels, other assays are required, including the test of its effects on $\mathrm{Na}_{\mathrm{V}} \mathrm{S}$ 1.7, 1.8 and 1.9, which are critically involved in pain mechanisms. Another possible target of these toxins, as observed for $\mathrm{r} \Gamma$-ctenitoxin-Pn1a $[38,39]$ is the NMDA receptor, which could also be involved in the observed antinociceptive effects. Other studies are in progress to try to clarify this point.

\section{Conclusions}

In the present study, we reveal that $\delta$-CNTX-Pn1a, a peptide isolated from the venom of Phoneutria nigriventer spider and previously characterized as an insect toxin, shows a clear analgesic effect in three different in vivo pain models. Moreover, we show, for the first time, the involvement of $\mathrm{CB}_{1}$ cannabinoid receptor and $\mu$ and $\delta$ opioid receptors in the antinociceptive effect of $\delta$-CNTX-Pn1a. Taken together, our results may contribute for the development of novel therapeutic agents of a wide spectrum to manage pain, although studies are still necessary to better clarify the mechanisms involved in the effects of $\delta$-CNTX-Pn1a.

\section{Material and Methods}

\subsection{Animals}

Male adult Wistar rats weighing 180-200 g were kept in a home cage environment with free access to water and food. Room temperature was maintained at $22 \pm 2{ }^{\circ} \mathrm{C}$ with a $12-12 \mathrm{~h}$ light-dark cycle (lights on at 6:00 a.m.). Animals were acclimatized and familiarized with the experimental room for at least 1 day before testing. All experiments were carried out according to the current guidelines for the care of laboratory animals and ethical guidelines for investigations of experimental pain in conscious animals [51], and were approved by the Ethics Committee on Animal Experimentation of the Federal University of Minas Gerais (protocol number: 102/2012 from 4 July 2012).

\subsection{Drugs}

The following drugs and chemicals were used: $\delta$-CNTX-Pn1a was purified by a combination of preparative reverse phase HPLC (RP-HPLC), ion exchange HPLC and analytical reverse phase HPLC as previously described [52]. $\mu$-Conotoxin MVIIA was purchased from Latoxan (Valence, France). Carrageenan (Sigma, St Louis, MO, USA), Prostaglandin E (Enzo Life Sciences, Farmingdale, NY, USA), AM251 ( $N$-(piperidin-1-yl)-5-(4-iodophenyl)-1-(2,4-dichlorophenyl)-4-methyl-1H-pyrazole-3carboxamide; Tocris, Pittsburg, PA, USA), AM630 (6-iodo-2-methyl-1-[2-(4-morpholinyl)ethyl]-1H-indol -3-yl(4-ethoxyphenyl) methanone Tocris, Pittsburgh, PA, USA), Naloxone (Sigma, St. Louis, MO, USA), Clocinnamox (Tocris, Pittsburgh, PA, USA), Naltrindole (Tocris, Pittsburgh, PA, USA), Nor-BNI (Nor-Binaltorphimine dihydrochloride; Sigma, St. Louis, MO, USA) were dissolved as follows: $\mathrm{PGE}_{2}$ (2\% ethanol in saline); AM251 and AM630 (12\% DMSO in saline); Carrageenan, 8 -CNTX-Pn1a, $\mu$-Conotoxin MVIIA (MVIIA), Naloxone, Clocinnamox, Naltrindole and Nor-BNI (saline).

\subsection{Drug Treatments}

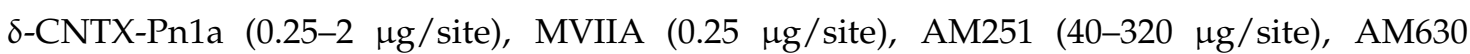

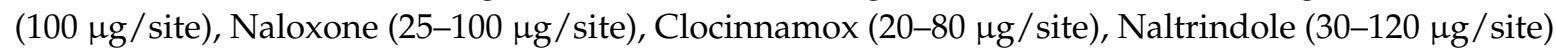
and Nor-BNI ( $50 \mu \mathrm{g} / \mathrm{site}$ ) were administered through intrathecal (i.t.) route, according to Mestre and co-authors [53]. The i.t. injections were delivered in a volume of $20 \mu \mathrm{L} /$ site per rat. $\delta$-CNTX-Pn1a $(5 \mu \mathrm{g} /$ site $)$, Carrageenan $(250 \mu \mathrm{g} /$ site $)$ and Prostaglandin $E_{2}(2 \mu \mathrm{g} / \mathrm{site})$ were administered through intraplantar route (ipl.) in a volume of 50 or $100 \mu \mathrm{L}$. 


\subsection{Carrageenan-Induced Inflammatory Hyperalgesia}

Male rats received a $100-\mu \mathrm{L}$ intradermal injection of carrageenan $(2.5 \mathrm{mg} / \mathrm{mL}$ in isotonic saline $)$ into the right hind paw. $\delta$-CNTX-Pn1a $(5 \mu \mathrm{g} / \mathrm{site})$ was administered through intraplantar route in different times after $\mathrm{Cg}$ injection. The nociceptive threshold was evaluated before and hourly after $\delta$-CNTX-Pn1a administration.

\subsection{Prostaglandin $E_{2}$-Induced Nociceptive Hyperalgesia}

Male rats received a $100 \mu \mathrm{L}$ intradermal injection of $\mathrm{PGE}_{2}\left(0.02 \mathrm{mg} / \mathrm{mL}\right.$ of $\mathrm{PGE}_{2}$, stored in ethanol, diluted in isotonic saline) into the right hind paw. $\delta$-CNTX-Pn1a $(0.25,0.5,1,2 \mu \mathrm{g} / \mathrm{site})$ was intrathecaly administered $2 \mathrm{~h}$ and $55 \mathrm{~min}$ after $\mathrm{PGE}_{2}$ injection. The nociceptive threshold was evaluated after $\delta$-CNTX-Pn1a administration, every ten minutes.

\subsection{Nociceptive Test}

The nociceptive threshold was measured according to the rat paw pressure test described by Randall and Selitto [54]. We used an analgesimeter (Ugo Basile, Varese, Italy) with a cone-shaped paw presser with a rounded tip, which applies a linearly increasing force to the rat's hind paw. The weight (g) required to elicit a nociceptive response (paw flexion) was determined as being the nociceptive threshold. A cutoff value of $300 \mathrm{~g}$ was used to minimize damage to the paws. The nociceptive threshold was measured in the right paw and determined as the average of three consecutive trials recorded before and various times after injection of the hyperalgesic agents. The same nociceptive thresholds were measured by two different experimenters.

\subsection{Induction of Neuropathy}

For the induction of peripheral neuropathy, male rats were first anesthetized $(60 \mathrm{mg} / \mathrm{kg}$ of ketamine plus $9 \mathrm{mg} / \mathrm{kg}$ of xylazine hydrochloride, intramuscular). Then, a partial constriction of the right sciatic nerve was performed using a previously described procedure [55]. In sham-operated rats, the control group, the nerve was only exposed without any ligation. Fourteen days after the surgical procedure the mechanical sensitivity was measured and, if the neuropathic pain effectiveness was established, the tests were performed. Rats not submitted to surgical intervention and not treated were labeled as naive. In this model of pain, $\delta$-CNTX-Pn1a $(0.5 \mu \mathrm{g} / \mathrm{site})$ was intrathecaly administered [53].

\subsection{Statistical Analysis}

Data were analyzed for statistical significance by one-way ANOVA analysis of variance followed by Bonferroni's test. The minimum level of significance considered was $p<0.05$. All graphics and analyses were performed using Prisma 5.0. (GraphPad Software Inc, San Diego, CA, USA).

Acknowledgments: This study received financial support from INCTTox (INCTTOX 573790/2008-6), Fundação de Amparo à Pesquisa do Estado de Minas Gerais (Fapemig), Capes-Toxinologia (Capes 063/10-23038.006280/2011-07), Conselho Nacional de Desenvolvimento Científico e Tecnológico (CNPq). We would like to acknowledge Dr. Marie France Martin Eauclaire for reviewing this manuscript.

Author Contributions: Maria Elena de Lima proposed the project and, together with Igor Dimitri G. Duarte, supervised the research and revised this paper. Marta N. Cordeiro, Márcia Helena Borges and Suely G. Figueiredo isolated the toxin and performed its biochemical characterization. Renata C.M. Ferreira and Bruna Luiza Emerich performed the nociceptive experiments and data analyses, besides writing the paper. Adriano M.C. Pimenta reviewed the manuscript and participated in discussions during the work. All authors contributed extensively to the work presented in this paper.

Conflicts of Interest: The authors declare no conflicts of interest. 


\section{Abbreviations}

The following abbreviations are used in this manuscript:

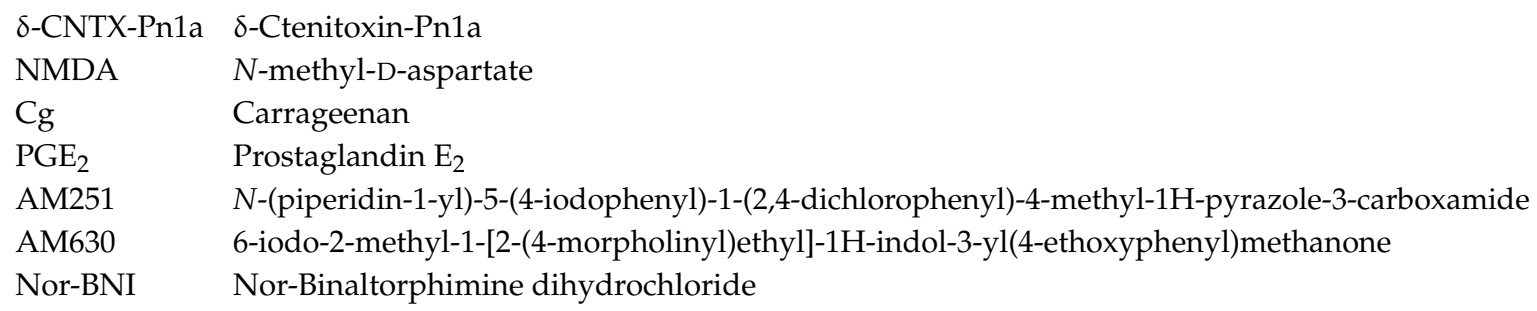

\section{References}

1. Harper, D. Online Etymology Dictionary, "Penal-Etymology". Available online: http://www.etymonline. com/index.php?term=penal\&allowed_in_frame $=0$ (accessed on 17 January 2016).

2. Rajendra, W.; Armugam, A.; Jeyaseelan, K. Toxins in anti-nociception and anti-inflammation. Toxicon 2004, 44, 1-17. [CrossRef] [PubMed]

3. Pineda, S.S.; Undheim, E.A.; Rupasinghe, D.B.; Ikonomopoulou, M.P.; King, G.F. Spider venomics: Implications for drug discovery. Future Med. Chem. 2014, 6, 1699-1714. [CrossRef] [PubMed]

4. King, G. The future of venoms-based drug discovery: An interview with Glenn King. Future Med. Chem. 2014, 6, 1613-1615. [CrossRef] [PubMed]

5. Castro, Jr.; Dalmolin, G.D.; da Silva, J.F.; Gomez, M.V. Uso de Toxinas Animais para o Tratamento da Dor: Fundamentos e Aplicações. In Biotecnologia Aplicada à Saúde: Fundamentos e Aplicações; Resende, R.R., Soccol, C.R., Eds.; Publisher: Blucher, Brazil, 2015; Volume 1, pp. 575-609. (In Portuguese)

6. Sylvie, D. Pain Modulating Peptides in Spider Venoms: Good and Evil. In Spider Venom; Gopalakrishnakone, P., Corzo, G.A., Diego-Garcia, E., de Lima, M.E., Eds.; Springer: Amsterdam, The Netherlands, 2015; Volume 1, pp. 121-154.

7. De Lima, M.E.; Torres, F.S.; Magalhães, B.L.E.; Freitas, A.C.N. Perspectivas inovadoras para o uso terapêutico de toxinas da aranha "armadeira" Phoneutria nigriventer (Keyserling, 1891) na dor e na disfunção erétil. In Biotecnologia Aplicada à Saúde: Fundamentos e Aplicações; Resende, R.R., Soccol, C.R., Eds.; Blucher: São Paulo, Brazil, 2015; Volume 1, pp. 539-572. (In Portuguese)

8. Chen, B.; Ji, Y. Antihyperalgesia effect of BmK AS, a scorpion toxin, in rat by intraplantar injection. Brain Res. 2002, 952, 322-326. [CrossRef]

9. De lima, M.E.; Stankiewicz, M.; Hamon, A.; Figueiredo, S.G.; Cordeiro, M.N.; Diniz, C.R.; Martin-Eauclaire, M.-F.; Pelhate, M. The toxin Tx4(6-1) from the spider Phoneutria nigriventer slows down $\mathrm{Na}^{+}$ current inactivation in insect CNS via binding to receptor site 3. J. Insect Physiol. 2002, 48, 53-61. [CrossRef]

10. Rosa, F.; Trevisan, G.; Rigo, F.K.; Tonello, R.; Andrade, E.L.; Cordeiro, M.N.; Calixto, J.B.; Gomez, M.V.; Ferreira, J. Ph $\alpha 1 \beta$, a peptide from the venom of the spider Phoneutria nigriventer shows antinociceptive effects after continuous infusion in a neuropathic pain model in rats. Anesth Anal. 2014, 119, 196-202. [CrossRef] [PubMed]

11. De Souza, A.H.; da Costa Lopes, A.M.; Castro, C.J., Jr.; Pereira, E.M.; Klein, C.P.; da Silva, C.A., Jr.; da Silva, J.F.; Ferreira, J.; Gomez, M.V. The effects of Ph $\alpha 1 \beta$, a spider toxin, calcium channel blocker, in a mouse fibromyalgia model. Toxicon 2014, 81, 37-42. [CrossRef] [PubMed]

12. Da Silva, J.F.; Castro-Junior, C.J.; Oliveira, S.M.; Dalmolin, G.D.; Silva, C.R.; Vieira, L.B.; Diniz, D.M.; Cordeiro, M.N.; Ferreira, J.; Souza, A.H.; et al. Characterization of the antinociceptive effect of PhTx3-4, a toxin from Phoneutria nigriventer, in models of thermal, chemical and incisional pain in mice. Toxicon 2015, 108, 53-61. [CrossRef] [PubMed]

13. Olivera, B.; Bulaj, G.; Garrett, J.; Terlau, H.; Imperial, J. Peptide Toxins from the venoms of cone snails and other toxoglossan gastropods. In Animal Toxins: State of the Art, Perspectives in Health and Biotechnology; de Lima, M.E., Pimenta, A.M.C., Martin-Eauclaire, M.F., Zingali, R.B., Hochat, H., Eds.; Editora UFMG: Belo Horizonte, Brazil, 2009; Volume 1, pp. 25-48.

14. De Marco Almeida, F.; de Castro Pimenta, A.M.; Oliveira, M.C.; de Lima, M.E. Venoms, toxins and derivatives from the Brazilian fauna: Valuable sources for drug discovery. Sheng Li Xue Bao 2015, 67, 261-270. [PubMed] 
15. Wallace, M.S. Ziconotide: A new nonopioid intrathecal analgesic for the treatment of chronic pain. Expert. Rev. Neurother. 2006, 6, 1423-1428. [CrossRef] [PubMed]

16. McGivern, J.G. Ziconotide: A review of its pharmacology and use in the treatment of pain. Neuropsychiatr. Dis. Treat. 2007, 3, 69-85. [CrossRef] [PubMed]

17. Parolaro, D.; Rubino, T.; Viganò, D.; Massi, P.; Guidali, C.; Realini, N. Cellular mechanisms underlying the interaction between cannabinoide and opioid system. Curr. Drug Targets 2010, 11, 393-405. [CrossRef] [PubMed]

18. Desroches, J.; Beaulieu, P. Opioids and cannabinoids interactions: Involvement in pain management. Curr. Drug Targets 2010, 11, 462-473. [CrossRef] [PubMed]

19. Konno, K.; Picolo, G.; Gutierrez, V.P.; Brigatte, P.; Zambelli, V.O.; Camargo, A.C.; Cury, Y. Crotalphine, a novel potent analgesic peptide from the venom of the South American rattlesnake Crotalus durissus terrificus. Peptides 2008, 29, 1293-1304. [CrossRef] [PubMed]

20. Machado, F.C.; Zambelli, V.O.; Fernandes, A.C.; Heimann, A.S.; Cury, Y.; Picolo, G. Peripheral interactions between cannabinoid and opioid systems contribute to the antinociceptive effect of crotalphine. Br. J. Pharmacol. 2014, 171, 961-972. [CrossRef] [PubMed]

21. Martin-Eauclaire, M.F.; Abbas, N.; Sauze, N.; Mercier, L.; Berge-Lefranc, J.L.; Condo, J.; Bougis, P.E.; Guieu, R. Involvement of endogenous opioid system in scorpion toxin-induced antinociception in mice. Neurosci. Lett. 2010, 482, 45-50. [CrossRef] [PubMed]

22. Freitas, A.C.; Pacheco, D.F.; Machado, M.F.; Carmona, A.K.; Duarte, I.D.; de Lima, M.E. PnPP-19, a spider toxin analogue, induces peripheral antinociception through opioid and cannabinoid receptors and inhibition of Neutral endopeptidase. Br. J. Pharmacol. 2016, 7. [CrossRef]

23. Borges, M.H.; de Lima, M.E.; Stankiewiscz, M.; Pelhate, M.; Cordeiro, M.N.; Beirão, P.S.L. Structural and functional diversity in the venom of spiders of the genus Phoneutria. In Animal Toxins: State of the Art. Perspectives on Health and Biotechnology; de Lima, M.E., Pimenta, A.M.C., Martin-Eauclaire, M.F., Zingali, R.B., Hochat, H., Eds.; Editora UFMG: Belo Horizonte, Brazil, 2009; Volume 1, pp. 291-312.

24. De Lima, M.E.; Figueiredo, S.F.; Matavel, A.; Nunes, K.P.; da Silva, C.N.; de Marco Almeida, F.; Diniz, M.R.V.; do Cordeiro, M.N.; Stankiewicz, M.; Beirão, P.S.L. Phoneutria nigriventer Venom and Toxins: A Review. In Spider Venom; Gopalakrishnakone, P., Corzo, G.A., Diego-Garcia, E., de Lima, M.E., Eds.; Springer: Amsterdam, The Netherlands, 2015; Volume 1, pp. 71-100.

25. Martin-Moutot, N.; Mansuelle, P.; Alcaraz, G.; dos Santos, R.G.; Cordeiro, M.N.; de Lima, M.E.; Seagar, M.; van Renterghem, C. Phoneutria nigriventer toxin 1: A novel, state-dependent inhibitor of neuronal sodium channels that interacts with micro conotoxin binding sites. Mol. Pharmacol. 2006, 69, 1931-1937. [CrossRef] [PubMed]

26. Matavel, A.; Fleury, C.; Oliveira, L.C.; Molina, F.; de Lima, M.E.; Cruz, J.S.; Cordeiro, M.N.; Richardson, M.; Ramos, C.H.; Beirão, P.S. Structure and activity analysis of two spider toxins that alter sodium channel inactivation kinectics. Biochemistry 2009, 48, 3078-3088. [CrossRef] [PubMed]

27. Leão, R.M.; Cruz, J.S.; Diniz, C.R.; Cordeiro, M.N.; Beirão, P.S. Inhibition of neuronal high-voltage activated calcium channels by the omega-Phoneutria nigriventer Tx3-3 peptide toxin. Neuropharmacology 2000, 39, 1756-1767. [CrossRef]

28. Dos Santos, R.G.; van Renterghem, C.; Martin-Moutot, N.; Mansuelle, P.; Cordeiro, M.N.; Diniz, C.R.; Mori, Y.; de Lima, M.E.; Seagar, M. Phoneutria nigriventer omega-phonetoxin IIA blocks the $\mathrm{Ca}_{\mathrm{v} 2}$ family of calcium channels and interacts with omega-conotoxin-binding sites. J. Biol. Chem. 2002, 277, 13856-13862. [CrossRef] [PubMed]

29. Vieira, L.B.; Kushmerick, C.; Hildebrand, M.E.; Garcia, E.; Stea, A.; Cordeiro, M.N.; Richardson, M.; Gomez, M.V.; Snutch, T.P. Inhibition of high voltage-activated calcium channels by spider toxin PnTx3-6. J. Pharmacol. Exp. Ther. 2005, 314, 1370-1377. [CrossRef] [PubMed]

30. Kushmerick, C.; Kalapothakis, E.; Beirão, P.S.; Penaforte, C.L.; Prado, V.F.; Cruz, J.S.; Diniz, C.R.; Cordeiro, M.N.; Gomez, M.V.; Romano-Silva, M.A.; et al. Phoneutria nigriventer toxin Tx3-1 blocks A-type K+ currents controlling $\mathrm{Ca}^{2+}$ oscillation frequency in GH3 cells. J. Neurochem. 1999, 72, 1472-1481. [CrossRef] [PubMed]

31. Figueiredo, S.G.; Garcia, M.E.L.-P.; Valentim, A.C.; Cordeiro, M.N.; Diniz, C.R.; Richardson, M. Purification and amino acid sequence of the insecticidal neurotoxin Tx4(6-1) from the venom of the "armed" spider Phoneutria nigriventer (Keys). Toxicon 1995, 33, 83-93. [CrossRef] 
32. Figueiredo, S.G.; de Lima, M.E.; Cordeiro, M.N.; Diniz, C.R.; Pattend, D.; Halliwelld, R.F.; Gilroyd, J.; Richardson, M. Purification and amino acid sequence of a highly insecticidal toxin from the venom of the Brazilian spider Phoneutria nigriventer which inhibits NMDA-evoked currents in rat hippocampal neurons. Toxicon 2001, 39, 309-317. [CrossRef]

33. Oliveira, L.C.; de Lima, M.E.; Pimenta, A.M.C.; Mansuelle, P.; Rochat, H.; Cordeiro, M.N.; Richardson, M.; Figueiredo, S.G. PnTx4-3, a new insect toxin from Phoneutria nigriventer venom elicits the glutamate uptake inhibition exhibited by PhTx4 toxic fraction. Toxicon 2003, 42, 793-800. [CrossRef] [PubMed]

34. De Lima, M.E.; Figueiredo, S.G.; Pimenta, A.M.; Santos, D.M.; Borges, M.H.; Cordeiro, M.N.; Richardson, M.; Oliveira, L.C.; Stankiewicz, M.; Pelhate, M. Peptides of arachnid venoms with insecticidal activity targeting sodium channels. Comp. Biochem. Physiol. C Toxicol. Pharmacol. 2007, 146, 264-279. [CrossRef] [PubMed]

35. Paiva, A.L.; Matavel, A.; Peigneur, S.; Cordeiro, M.N.; Tytgat, J.; Diniz, M.R.V.; de Lima, M.E. Differential effects of the recombinant toxin PnTx4(5-5) from the spider Phoneutria nigriventer on mammalian and insect sodium channels. Biochimie 2016, 121, 326-335. [CrossRef] [PubMed]

36. King, G.F.; Gentz, M.C.; Escoubas, P.; Nicholson, G.M. A rational nomenclature for naming peptide toxins from spiders and other venomous animals. Toxicon 2008, 52, 264-276. [CrossRef] [PubMed]

37. Penaforte, C.L.; Prado, V.F.; Prado, M.A.; Romano-Silva, M.A.; Guimarães, P.E.; de Marco, L.; Gomez, M.V.; Kalapothakis, E. Molecular cloning of cDNAs encoding insecticidal neurotoxic peptides from the spider Phoneutria nigriventer. Toxicon 2000, 38, 1443-1449. [CrossRef]

38. Oliveira, C.F.B. Estudo da ação antihiperalgésica da toxina PnTx4(5-5) do veneno da aranha armadeira Phoneutria nigriventer (Keyserling, 1981). Master's Thesis, Universidade Federal de Minas Gerais, Belo Horizonte, MG, Brasil, 2010. (In Portuguese).

39. Silva, F.R.; Batista, E.M.L.; Gomez, M.V.; Kushmerick, C.; da Silva, J.F.; Cordeiro, M.N.; Vieira, L.B.; Ribeiro, F.M. The Phoneutria nigriventer spider toxin, PnTx4-5-5, promotes neuronal survival by blocking NMDA receptors. Toxicon 2016, 112, 16-22. [CrossRef] [PubMed]

40. Bleakman, D.; Alt, A.; Nisenbaum, E.S. Glutamate receptors and pain. Semin. Cell Dev. Biol. 2006, 17, 592-604. [CrossRef] [PubMed]

41. Chizh, B.A. Low dose ketamine: A therapeutic and research tool to explore $N$-methyl-D-aspartate (NMDA) receptor-mediated plasticity in pain pathways. J. Psychopharmacol. 2007, 21, 259-271. [CrossRef] [PubMed]

42. Kuhn, D.C.; Willis, A.L. Proceedings: Prostaglandin $E_{2}$, inflammation and pain threshold in rat paws. Br. J. Pharmacol. 1973, 49, 183-184.

43. Picolo, G.; Giorgi, R.; Cury, Y. Delta-opioid receptors and nitric oxide mediate the analgesic effect of Crotalus durissus terrificus snake venom. Eur. J. Pharmacol. 2000, 391, 55-62. [CrossRef]

44. Picolo, G.; Cury, Y. Peripheral neuronal nitric oxide synthase activity mediates the antinociceptive effect of Crotalus durissus terrificus snake venom, a delta- and kappa-opioid receptor agonist. Life Sci. 2004, 75, 559-573. [CrossRef] [PubMed]

45. Diochot, S.; Baron, A.; Salinas, M.; Douguet, D.; Scarzello, S.; Dabert-Gay, A.S.; Debayle, D.; Friend, V.; Alloui, A.; Lazdunski, M.; et al. Black mamba venom peptides target acid-sensing ion channels to abolish pain. Nature 2012, 490, 552-555. [CrossRef] [PubMed]

46. Dalmolin, G.D.; Silva, C.R.; Rigo, F.K.; Gomes, G.M.; Cordeiro, M.N.; Richardson, M.; Silva, M.A.; Prado, M.A.; Gomez, M.V.; Ferreira, J. Antinociceptive effect of Brazilian armed spider venom toxin Tx3-3 in animal models of neuropathic pain. Pain 2011, 152, 2224-2232. [CrossRef] [PubMed]

47. Willis, A.L. Parallel assay of prostaglandin-like activity in rat inflammatory exudate by means of cascade superfusion. J. Pharm. Pharmacol. 1969, 21, 126-128. [CrossRef] [PubMed]

48. Di Rosa, M.; Giroud, J.P.; Willoughby, D.A. Studies on the mediators of the acute inflammatory response induced in rats in different sites by carrageenan and turpentine. J. Pathol. 1971, 104, 15-29. [CrossRef] [PubMed]

49. Bridges, D.; Thompson, S.W.; Rice, A.S. Mechanisms of neuropathic pain. Br. J. Anaesth. 2001, 87, 12-26. [CrossRef] [PubMed]

50. Oliveira, S.M.; Silva, C.R.; Trevisan, G.; Villarinho, J.G.; Cordeiro, M.N.; Richardson, M.; Borges, M.H.; Castro, C.J., Jr.; Gomez, M.V.; Ferreira, J. Antinociceptive effect of a novel armed spider peptide Tx3-5 in pathological pain models in mice. Pflugers Arch. Eur. J. Physiol. 2016, 22, 1-14. [CrossRef] [PubMed]

51. Zimmermann, M. Ethical guidelines for investigations of experimental pain in conscious animals. Pain 1983, 16, 109-110. [CrossRef] 
52. Richardson, M.; Pimenta, A.M.; Bemquerer, M.P.; Santoro, M.M.; Beirão, P.S.; Lima, M.E.; Figueiredo, S.G.; Bloch, C.J.; Vasconcelos, E.A.; Campos, F.A.; et al. Comparison of the partial proteomes of the venoms of Brazilian spiders of the genus Phoneutria. Comp. Biochem. Physiol. C Toxicol. Pharmacol. 2006, 142, 173-187. [CrossRef] [PubMed]

53. Mestre, C.; Pélissier, T.; Fialip, J.; Wilcox, G.; Eschalier, A. A method to perform direct transcutaneous intrathecal injection in rats. J. Pharmacol. Toxicol. Methods 1994, 32, 197-200. [CrossRef]

54. Randall, L.O.; Selitto, J.J. A method for measurement of analgesic activity on inflamed tissues. Arch. Int. Pharmacody 1957, 111, 409-419.

55. Bennett, G.J.; Xie, Y.K. A peripheral mononeuropathy in rat that produces disorders of pain sensation like those seen in man. Pain 1988, 33, 87-107. [CrossRef]

(C) 2016 by the authors; licensee MDPI, Basel, Switzerland. This article is an open access article distributed under the terms and conditions of the Creative Commons Attribution (CC-BY) license (http://creativecommons.org/licenses/by/4.0/). 